\title{
Concepções acerca da inclusão de um laboratório de acesso remoto com experimentos de física contemporânea
}

Arquimedes Luciano arquimedes.luciano@hotmail.com 0000-0002-7514-0425 Universidade Estadual de Maringá

Polonia Altoe Fusinato altoepoly@gmail.com 0000-0002-4698-8574 $\frac{0000-0002-4698-8574}{\text { Universidade Estadual de }}$ Maringá/PCM

\section{RESUMO}

A física moderna e contemporânea constitui um campo científico muito desenvolvido, sendo a base teórica de funcionamento de inúmeros dispositivos, produzindo, assim, vasta gama de aplicações utilizadas na vida cotidiana da sociedade atual. Diversos são os problemas associados à inclusão desses temas no ensino médio, entre estes se podem citar os custos de implantação de laboratórios com experimentos de temas de física moderna para todas as escolas da rede pública. Além de tais custos também há a necessidade de preparação docente, para a aplicação de uma estratégia metodológica que permita a discussão de tais temas com os alunos, garantindo o aprendizado. Para esta pesquisa o objetivo de investigar o potencial pedagógico de um laboratório de acesso remoto para o ensino de física moderna e contemporânea (FMC) no ensino médio. $E$, para permitir a obtenção do objetivo geral acima proposto, elencamos como objetivos específicos de nosso trabalho identificar, por meio das atividades de ensino de FMC, a influência do uso de um laboratório de acesso remoto no desenvolvimento da atividade experimental com alunos do terceiro ano do ensino médio junto à componente curricular física; analisar a utilização de atividades experimentais enquanto estratégia metodológica para fornecer benefícios para a aprendizagem de conceitos da FMC. Foi desenvolvido um laboratório de acesso remoto e o experimento utilizado nesta investigação foi uma câmara de nuvens. A sequência de ensino utilizada garantiu ações delineadas pelo ciclo descrição-execuçãoreflexão-depuração, proposto pela teoria construcionista, de Valente e Papert. Durante as ações foram conduzidas entrevistas junto aos professores e questionários foram aplicados aos alunos participantes. As respostas transcritas foram analisadas, segundo a técnica de análise textual discursiva, tais repostas permitiram verificar as potencialidades de uso do laboratório de acesso remoto como facilitador da inclusão de tópicos de FMC no ensino médio.

PALAVRAS-CHAVE: Construcionismo. Acesso remoto. Física moderna. Ensino médio. 


\section{INTRODUÇÃO}

A utilização de atividades experimentais no ensino de física, por mais de um século, tem pretendido promover aproximação maior do educando com os fenômenos físicos (HOFSTEIN, 2007). Tal aproximação pode servir de elemento motivador ao aprendiz. A componente curricular física, cursada no ensino médio, deve, permitir ao educando, que no final dessa etapa educacional, tenha desenvolvido aptidão para conseguir interpretar e resolver problemas sobre aspectos matemáticos, associados a situações conceituais idealizadas acerca de fenômenos físicos (ROBERTS, 2004).

Desta forma atividades experimentais utilizando laboratórios de acesso remoto tem sido discutidas por autores como Lelevé et al (2003), Ma e Nickerson (2006) e Lopes (2007). O que nos motivou a investigar as potencialidades pedagógicas de um laboratório de acesso remoto para ensino de física moderna.

Dentre as competências esperadas quanto aos conhecimentos físicos de um egresso do ensino médio, citadas nos PCN's, podemos elencar que o estudante deve ter a capacidade de perceber o papel desempenhado pelo conhecimento físico no desenvolvimento da tecnologia e a estreita relação histórica entre ciência e tecnologia (BRASIL, 2002). Notamos, nesse trecho, a clara objetividade de se tratar de assuntos correlatos à FMC no ensino médio, quando se busca o entendimento sobre temas científicos de física publicados em eras mais recentes. Como o caso da teoria da relatividade einsteiniana e a teoria quântica, de Max Born. Determinados aspectos da física moderna são considerados indispensáveis para conduzir os aprendizes a uma compreensão mais ampla da estruturação da matéria e consequentemente de novos materiais, cristais líquidos e lasers, presentes em dispositivos tecnológicos de uso cotidiano (BRASIL, 2002). Faz-se então necessário que tais aspectos e conceitos sejam discutidos e aproximados à vivência escolar dos alunos.

Nesse viés, o emprego de atividades experimentais de temas tratados em FMC pode auxiliar a motivação e compreensão dos alunos quanto à aprendizagem desses temas mediante a aproximação dos conceitos a partir do contato com fenômenos físicos correlatos a essa área do saber. Contudo, em diversas regiões, torna-se complexa a tarefa de instrumentar escolas com equipamentos capazes de permitir a realização de tais práticas pois tal instrumentalização demanda recursos financeiros, bem como capacitar rapidamente grandes grupos de docentes, capazes de realizar tais atividades, o que também é considerada tarefa extremamente morosa.

Uma alternativa ao problema de disseminação ágil de equipamentos laboratoriais, principalmente no que se refere a equipamentos mais caros, é a utilização de laboratórios de acesso remoto. Esses laboratórios consistem na extensão de um ou mais instrumentos de medição real através de uma rede de dados distribuída (OGIBOSKI, 2007). Segundo Ma e Nickerson (2006), um laboratório remoto é caracterizado por mediar a realidade, de modo similar a um laboratório, cujos alunos possam atuar diretamente, estando, contudo, distantes do operador, portanto, requerendo hardware e software específicos para realizar essa mediação.

Nesse modelo, o aprendiz tem acesso aos equipamentos e realiza a investigação experimental, visualizando em tempo real na tela de um computador 
disponível no laboratório de informática da escola as imagens do equipamento que utiliza para sua prática laboratorial. Ainda, a coleta de dados ocorre de modo automatizado, facilitando a sua organização frente aos dados obtidos no experimento, permitindo que o tempo de utilização seja mais bem aproveitado e que o foco do educando se mantenha em compreender os fenômenos físicos, correlatos ao experimento em andamento. Segundo a teoria construcionista de Papert (2008), o computador sendo utilizado por um estudante, pode proporcionar as construções mentais por meio das relações existentes entre o abstrato e o concreto sendo visualizadas na tela da máquina. Utilizando a mesma linha de pensamento, pautamos nossas ações pedagógicas em fornecer possibilidades para que o estudante possa a partir da visualização do experimento produzir conexões mentais entre a teoria de física moderna estudada com as observações reveladas pela atividade experimental.

Do já exposto, percebemos a necessidade de a escola formar indivíduos que apresentem características que lhe permitam ter uma visão crítica de mundo, não necessariamente um proto cientista, contudo uma pessoa que tenha a capacidade de compreender as relações entre ciência e tecnologia que a cercam na sociedade atual. Segundo Valente (1999, p.33), "Para ser crítico, se envolver e participar das atividades na sociedade, assumir responsabilidades e desenvolver novas habilidades, é necessário o aluno compreender o que faz e não ser um mero executor de tarefas que são propostas".

Para Lévy (1999), existe enorme demanda educacional principalmente em países em desenvolvimento como o nosso, e temos de buscar soluções que estejam pautadas em técnicas que permitam ampliar o escopo de formação dos professores e alunos, sendo um caminho a utilização de ensino não presencial, mas com acesso à distância.

Contudo, o uso de qualquer ferramenta, incluindo os recursos tecnológicos, somente apresentará êxito, se bem orientada pelo professor. E, para tal, o professor também deve estar preparado em suas práticas letivas, por meio, por exemplo, de atividades de formação continuada (LEAL et. al. 2012). Pautamos nossa fala também em Maltempi (2000), que destaca que, para a prática do construcionismo, é necessário fundamentar as práticas docentes em ambientes de aprendizagem que promovam desafios e iniciativas, permitindo ao educando usar as novas tecnologias de informação no ensino e promovendo um aprendizado significativo, pois, segundo Papert (2008, p.135), "O tipo de conhecimento que as crianças mais precisam é o que as ajudará a obter mais conhecimento".

No presente trabalho apresentaremos um conjunto de análises de resultados sobre a utilização de um experimento de acesso remoto como elemento facilitador à inclusão do ensino de física moderna no ensino médio. A intervenção por nós realizada contou com a participação de dois professores de física do ensino médio do Núcleo Regional de Maringá e com 101 estudantes do terceiro ano do ensino médio de duas escolas públicas da rede estadual localizadas no município de Maringá, onde atuam estes docentes antes mencionados.

Nosso objetivo com esta intervenção foi identificar a correlação entre a inclusão da experimentação remota sobre radiação cósmica, e o aprendizado deste mesmo conceito frente a disciplina de física no ensino médio. 


\section{METODOLOGIA}

Os estudos que envolvem os conceitos relacionados a física moderna e contemporânea no ensino médio, tem em grande maioria o predomínio da abstração e da matematização. A questão da abstração, abordada por Pietrocolla (2005), remete à necessidade de apresentar aos alunos os conteúdos de FMC de maneira vinculada com a realidade e não apenas como um conceito distante e estéril. Essa questão proposta motivou a busca em compreendermos, a partir da análise do ensino dos conceitos de FMC, em que um laboratório de acesso remoto, por meio de experimentos envolvendo conteúdos com certo grau de complexidade, pode favorecer a aprendizagem de estudantes do ensino médio.

Caracterizamos nossa pesquisa dentro da vertente qualitativa, pois "os métodos da pesquisa qualitativa destacam a importância das várias perspectivas, reconhecendo que existem outras formas de visualizar e de explicar as coisas bem como formas e alternativas para mudá-las" (STAKE, 2011). Nosso envolvimento inicial se deu em preparar os docentes envolvidos com o conhecimento técnico dos equipamentos dispostos no laboratório de acesso remoto e, por meio de atividades construcionistas, permitir que compreendam a necessidade de mudança de metodologia no ensino médio. Também estávamos preocupados em atualizar os docentes quanto aos conteúdos a serem estudados. Desta forma os trabalhos desenvolvidos permitiram que tanto pesquisadores quanto sujeitos envolvidos com a pesquisa estivessem diretamente vinculados com o experimento.

Inicialmente atuamos levando os professores ao laboratório e os apresentando os equipamentos que seriam utilizados remotamente por meio do uso do computador em sala de aula. $O$ detector de radiação que utilizamos na atividade experimental é uma câmara de nuvens, que é um equipamento capaz de apresentar traços deixados em uma nuvem de álcool isopropílico, de partículas com alta energia quando atravessam a região da câmara. A seguir, na figura 1, apresentamos a imagem da câmara de nuvens instalada no laboratório de acesso remoto.

Figura 1: Câmara de Nuvens Utilizada

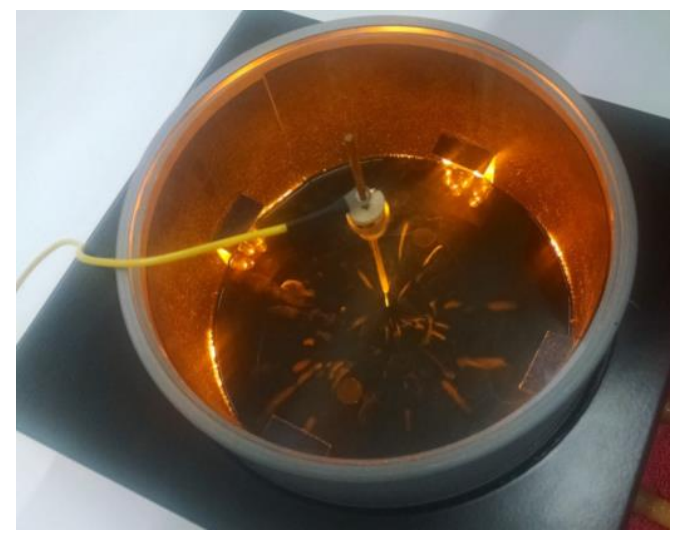

(Fonte: Autoria Própria)

Após o contato dos professores com os equipamentos (câmara de nuvens, computadores e câmera de transmissão de imagem). Discutimos assuntos relacionados à $\mathrm{FMC}$ e que envolvem o experimento do laboratório de acesso 
remoto. Posteriormente a esse momento também foram apresentados e discutidos com os professores participantes o referencial teórico deste trabalho, que se trata do construcionismo de Papert (2008), e a metodologia proposta para ser a norteadora do desenvolvimento das atividades, segundo Valente (1999). Esse autor apresenta o processo de aprendizagem por meio do ciclo descriçãoexecução-reflexão-depuração.

De modo a preparar os professores para as ações que seriam conduzidas, realizamos uma oficina sobre produção de sequência didática, concatenando os referenciais teóricos. Os professores, após participarem dessa oficina, elaboraram uma sequência didática seguindo os pressupostos de Zabala (1998), na qual selecionamos que atividades seriam desenvolvidas envolvendo o experimento de câmara de nuvens, disponível no laboratório de acesso remoto.

Nessa sequência didática, reforçamos a preocupação em utilizar o experimento seguindo os pressupostos do construcionismo como metodologia para que buscássemos garantir a efetividade do ciclo de atividades cognitivas de Valente e Canhette (1993). A finalidade dessa sequência didática foi que os professores pudessem aplicá-la em sala de aula, junto a seus alunos, com o intuito de que as atividades que contemplassem o uso do laboratório de acesso remoto como recurso didático fossem favoráveis à aprendizagem do conteúdo selecionado. A seguir apresentamos o quadro 1 que contém as atividades desenvolvidas com os professores participantes bem como a carga horária utilizada nas ações.

Quadro 1: Atividades desenvolvidas com os professores e carga horária

\begin{tabular}{|l|c|}
\hline \multicolumn{1}{|c|}{ Atividades Desenvolvidas } & Carga horária \\
\hline $\begin{array}{l}\text { Apresentação da câmara de nuvens e realização do experimento } \\
\text { presencial }\end{array}$ & 2 horas \\
\hline $\begin{array}{l}\text { Discussão sobre FMC - radiação cósmica e a interação da } \\
\text { radiação com a matéria }\end{array}$ & 2 horas \\
\hline $\begin{array}{l}\text { Apresentação sobre o funcionamento de um laboratório de } \\
\text { acesso remoto }\end{array}$ & 2 horas \\
\hline $\begin{array}{l}\text { Oficina acerca dos pressupostos construcionistas - o papel do } \\
\text { professor e o papel do aluno no construcionismo }\end{array}$ & 2 horas \\
\hline $\begin{array}{l}\text { Discussão da preparação de atividades construcionistas } \\
\text { utilizando o ciclo descrição-execução-reflexão-depuração }\end{array}$ & $\begin{array}{l}\text { Oficina de produção de sequência didática seguindo a teoria de } \\
\text { Antoni Zabala }\end{array}$ \\
\hline
\end{tabular}

(Fonte: Autoria Própria)

Após a sequência didática ser concluída os professores envolvidos aplicaram a mesma em suas respectivas escolas com os estudantes também participantes desta pesquisa. Na primeira aula da sequência didática se buscava instigar os alunos aos conceitos referentes à radiação cósmica, ao mesmo tempo em que se aplicou o questionário inicial que demarcava os saberes já detidos pelos alunos. Na segunda aula da sequência didática os alunos foram levados ao laboratório de informática e utilizando os computadores e a conexão à internet acessaram o site do laboratório de acesso remoto que permitiu que realizassem o experimento de observação de radiação cósmica por meio da câmara de nuvens remotamente. 
De modo a compreender as implicações de nossas ações durante a pesquisa e as possíveis conclusões que esta pesquisa qualitativa pode proporcionar, carecemos coletar informações durante a pesquisa. Segundo Lakatos e Marconi, temos que a coleta de dados é definida como "Etapa da pesquisa em que se inicia a aplicação dos instrumentos elaborados e das técnicas selecionadas, a fim de se efetuar a coleta dos dados previstos" (LAKATOS e MARCONI, 1996, p. 167).

A coleta de dados ocorreu em dois momentos, no início da pesquisa, para permitir que nos alinhássemos com a realidade dos atores, e no final para coletar as percepções dos atores sobre as interações.

Portanto, foram utilizados dois questionários para os alunos, com objetivos distintos, o primeiro objetivava levantar informações sobre os conhecimentos prévios dos alunos frente ao conteúdo de FMC e sua proximidade com as tecnologias da informação. No segundo questionário o objetivo era investigar as percepções dos alunos quanto ao aprendido a partir da intervenção realizada no que tange aos conceitos de FMC abordados.

Já com os docentes envolvidos, foram realizadas duas entrevistas semiestruturadas, uma no início das atividades e outra ao encerrar. Estas entrevistas foram individuais e gravadas em áudio e vídeo e realizadas no espaço do laboratório de acesso remoto e os questionários, respondidos pelos alunos nos respectivos colégios, sendo transcritas todas na íntegra, com o objetivo de relacionar as respostas dos professores com os relatos dos estudantes.

Os questionários tiveram seus dados digitalizados e foram analisados por meio de Análise Textual Discursiva, proposta por Roque Moraes e Maria do Carmo Galiazzi no artigo Uma tempestade de luz: a compreensão possibilitada pela análise textual discursiva (MORAES, 2003). Alguns dos resultados provenientes dos questionários permitiram realizar tabulações e produzir uma avaliação estatística quanto aos perfis dos envolvidos.

As transcrições das entrevistas, quando utilizadas, foram inclusas no corpo do texto, com uma indicação de quem foi o ator da pesquisa que emitiu aquela fala, utilizamos para identificação das transcrições os termos P1 e P2 para os professores envolvidos e $\mathrm{A} 1, \mathrm{~A} 2, \mathrm{~A} 3, \ldots$ para os estudantes participantes da pesquisa.

\section{RESULTADOS}

\section{A FÍSICA MODERNA E CONTEMPORÂNEA E O ENSINO MÉDIO}

Segundo a visão norteada pelos PCN's para o ensino de física no ensino médio, há mais que se oferecer ao aluno, pois as competências em física são firmadas no aprendiz quando este associa o conhecimento físico a situações cotidianas, impregnadas também de outros conhecimentos, permitindo a esse indivíduo que o conhecimento físico se estruture como conhecimento cultural e científico.

Determinados aspectos da FMC são considerados indispensáveis para conduzir os aprendizes a uma compreensão mais ampla da estruturação da matéria e consequentemente de novos materiais, cristais líquidos e lasers, presentes em dispositivos tecnológicos de uso cotidiano (BRASIL, 2002, p.19). 
Nesse sentido, faz-se necessário que tais aspectos e conceitos sejam discutidos e aproximados da vivência escolar dos alunos. Dessa forma, nesse tema pretendemos compreender os caminhos e direcionamentos da FMC no ensino médio. O tema foi subdivido em duas categorias de análise, que emergiram das falas produzidas pelos atores sociais envolvidos, sendo mescladas as falas dos professores e as respostas dos estudantes.

Os professores foram questionados com relaçãos à inclusão dos conceitos de FMC no ensino médio e as suas atuais potencialidades, bem como as ações de ordem das políticas educacionais no incentivo da utilização dos conceitos de FMC no cenário atual. Para os questionários os estudantes foram indagados a respeito de partículas de alta energia emitidas pelo Sol. As respostas produziram os dados que foram analisados.

\section{ESTRUTURA ESCOLAR E EXPERIMENTAÇÃO DE FMC}

A contemporaneidade vivida pelos alunos do ensino médio é permeada de resultados práticos da aplicação e desenvolvimento dos conceitos básicos da FMC. Como FMC consideramos o arcabouço teórico, formado pelas teorias subjacentes à teoria da relatividade e física quântica, de modo a distinguir da mecânica newtoniana e do eletromagnetismo maxwelliano, consideradas "física clássica" (HALLIDAY, RESNICK e WALKER, 2016).

Entretanto, por mais vivência com dispositivos tecnológicos que esses alunos tenham, o currículo adotado na escola ainda não contempla a inserção de tópicos de FMC. Entre os problemas evidenciados, a partir de nossa pesquisa, podemos elencar que a estrutura escolar não apresenta material laboratorial para a realização de experimentos de FMC.

Conforme a fala do professor P2, "mais ... o grande problema da escola inclusive de várias escolas é a completa inexistência de material especificamente de física que é o material mais caro". Além dessa observação, podemos também verificar a ausência de uma proposta de formação continuada com a intenção de garantir ao professor que este possa se preparar metodologicamente para intervir, proporcionando ações no ensino de FMC no ensino médio, Incluímos a fala do professor P1 que revela: "quando tem formação é local, da universidade junto com os professores, nada que venha lá de cima (se referindo à secretaria de educação do estado)". Tais falas corroboram a ideia de que o estudo de FMC no ensino médio, quando tratado, se faz na grande maioria das vezes em conceitos abstratos, dificultando o aprendizado do mesmo e deixando uma distância entre a realidade empregada na natureza e suas aplicações na sociedade.

Tal abstração desmotiva os estudantes para estudar tais conceitos, pois, segundo Pietrocola (2005), a física ensinada deve ser a real de modo a ser compreensível pelos alunos. Contudo Morin apresenta que "As ideias e teorias não refletem, mas traduzem a realidade" $(2003$, p 85$)$, portanto, tal autor nos mostra que a realidade de um indivíduo representa a ideia do indivíduo de realidade. Assim, foi de suma importância buscar a compreensão das ideias dos alunos e professores sobre FMC, especificadamente sobre física de partículas.

Durante as atividades de ensino utilizando a sequência didática, os da discussão acerca de uma matéria de jornal que destacava a problemática de 
uma tempestade solar. Logo após a discussão, estes alunos preencheram um questionário que tendia a coletar informações que permitiriam investigar sua compreensão acerca da existência de tais partículas.

Assim, por meio das respostas de um dos sujeitos da pesquisa, o aluno A14, que aponta: "Era possível ver o trajeto das partículas na câmara. Algumas desciam retas, outras faziam curva. Outras até mesmo desciam em espiral. Pelo que me lembro pude ver uns quatro tipos de trajeto diferentes". Nesse apontamento evidenciamos que o indivíduo, ao ter contato com a visualização do experimento, pôde associar a trajetória observável que a partícula, advinda do espaço ao adentrar a câmara de nuvens, deixou na nuvem de álcool isopropílico.

Tal percepção nos conduz a acreditar que ocorreu ao menos a compreensão de que as partículas elementares, estudadas anteriormente apenas de modo teórico, foram assimiladas como "objetos" do mundo real por esse aluno. 0 mesmo indivíduo, aluno A14, quando questionado sobre seus conhecimentos prévios acerca de tais partículas, nos responde: "não era de meu conhecimento. Eu sabia sobre a atmosfera e como ela nos protegia dos raios solares, mas era só isso". Então podemos verificar que houve mudança em sua concepção sobre a existência de tais partículas, correlacionando com a fala do professor P2, que estava junto à turma no momento da realização do experimento: "os alunos estavam empolgados, pois até os anos anteriores o conteúdo era sempre estudado como um acredite se puder e agora os alunos vivenciaram a possibilidade de ver ao menos as trajetórias deixadas pelas partículas".

Conforme sabemos, há urgente necessidade de incluir os conceitos e experimentos de $\mathrm{FMC}$ no ensino médio. Muitos são os trabalhos que nos apontam isso, poderíamos citar, por exemplo, os trabalhos de pesquisadores como Pietrocola (2005), Moreira (2012), Terrazan (1992), Brockington e Pietrocola (2005) Ostermann e Moreira (2000), que são expoentes que apontam a necessidade da inclusão de tais conteúdos no ensino médio. Porém é fundamental perceber que não há, de modo algum, mudanças significativas ocorrendo. Grande parte dessa ausência de mudanças pode ser observada na fala dos nossos entrevistados, no caso, tanto o professor P1 quanto o professor P2 revelam que não há uma política pública permanente que tenda a suplantar as mudanças necessárias, impostas pela lei de diretrizes e bases, desde o ano de 1996.

No caso específico de nossos entrevistados, estes apontam que as únicas ações nessa região, sugeridas partiram do Departamento de Física da Universidade Estadual de Maringá. Que propôs atividades para formação continuada de professores. De modo que trabalhos vêm sendo feitos no âmbito da formação continuada, mas são tentativas puramente pontuais. A fala do professor P2 nos aponta tais situações na formação docente continuada: "não há em nenhum aspecto uma política pública para ao menos fornecer equipamento para as nas escolas". Ainda o mesmo professor aponta que, pela redução da carga horária da disciplina de física, "Nos últimos quinze anos a carga horária de física já caiu a um terço, e a alternativa é cortar conteúdos então outros conteúdos são deixados de lado para permitir que os tópicos (FMC) sejam incluídos" (P2).

O que ocorre é uma substituição de conteúdos de modo que, conforme nos diz o professor P2: "conteúdos como mecânica de fluídos e capacitores são cortadas da ementa para que novos tópicos sejam incluídos". 
Entretanto o professor P1 e o professor P2 apontam que procuram fazer ações que permitam, aos poucos, integrar os tópicos de FMC na componente curricular de física. O professor P2 admite que "e vídeos que eu usei também né, do Brian Greene", o que indica que esse professor apresenta vídeos aos seus alunos com a temática de FMC.

Quanto ao que tange aos experimentos de FMC, o professor P2 descreve que "os itens experimentais utilizados são itens que comprei às minhas próprias expensas". Segundo o que nos falam tanto o Professor P1 quanto o Professor P2, a revelação que temos é de não abordarmos $\mathrm{FMC}$ no ensino médio em parte pelas contingências orçamentárias e falta de preocupação para que a FMC seja inclusa efetivamente no ensino médio. Desse modo, a FMC vem sendo tocada apenas superficialmente por esses professores durante as ações de ensino. Segundo P2, "Mas assim, sempre buscar de uma forma a linguagem mais simples possível. Para ninguém sair correndo assustado né".

Notamos que, ao compararmos as ideias de Taylor (1966), por meio da construção da câmara de nuvens de Taylor, com a situação atual da estrutura escolar, verificamos que, desde muito tempo, já se preocupava com a inclusão de temas de FMC. Porém tais possibilidades ainda estão distantes do nosso alunado no aspecto de ensino-aprendizagem, contudo esses mesmos alunos que estão afastados do aprendizado de FMC estão imersos em um mundo ocupado por dispositivos e fenômenos que são descritos por conceitos de FMC.

Apresentamos, no Gráfico 1 a seguir, a distribuição de alunos por tempo em que utilizam recursos da internet. Neste, agrupamos os indivíduos em seções por idade e por tempo de acesso à internet. Os indivíduos desse grupo analisado têm faixa etária média de 17,04 anos de idade e permanecem em média 3,34 h por dia conectados.

Gráfico 1: Distribuição de indivíduos por tempo médio de acesso à internet

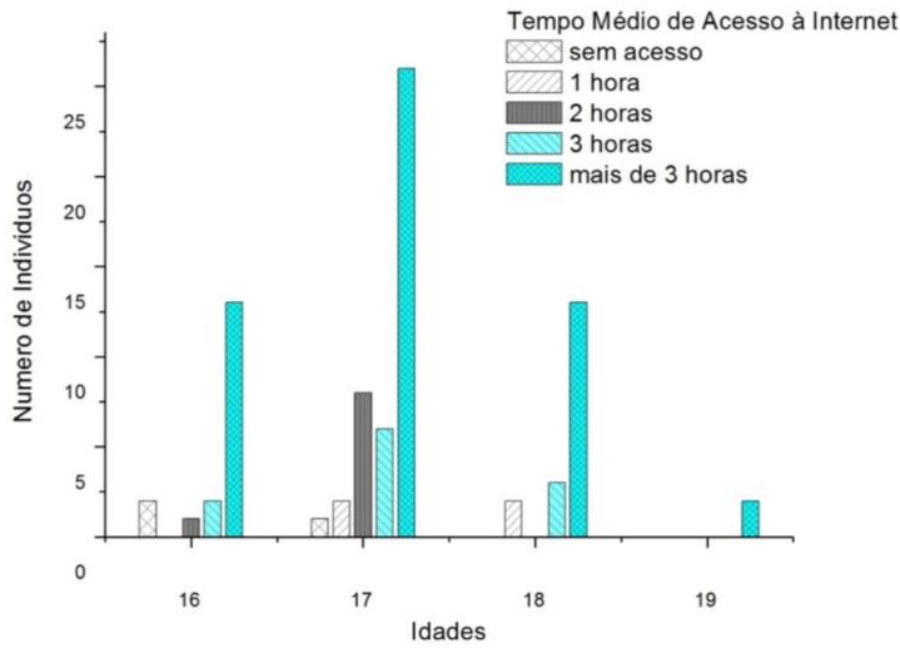

(Fonte: Autoria própria)

Pelos dados coletados, notamos que esses alunos permanecem grande parte de seus dias utilizando recursos de rede, o que representa uma proximidade destes com a abordagem tecnológica que propomos nesta pesquisa, em utilizar o computador e o acesso à internet como estratégia metodológica de ensino. 
Além de levantarmos as características etárias dos alunos, também realizamos a triangulação, buscando entender quanto tempo e por meio de que formas de dispositivos eles se conectam à internet. Foram questionados sobre atividades cotidianas, realizadas na rede, bem como o tempo médio diário de conexão. Entre as principais utilizações dessas conexões, estão as redes sociais e os jogos eletrônicos.

A importância de tal triangulação é efetivamente verificar a proximidade dos alunos do ensino médio com as tecnologias disponíveis, pois sabendo que atividades em rede os alunos realizam podemos planejar futuras ações pedagógicas que envolvam tais plataformas. Com a intencionalidade de melhora nas atividades de ensino. Outro ponto de destaque, observado no gráfico 1 , é a democratização do acesso à internet pois apenas dois indivíduos de todo o ensemble não possuíam conexão em casa com a rede mundial de computadores.

\section{A REALIDADE DAS PARTÍCULAS}

Conforme descrito na categoria anterior, o aluno das escolas estudadas se utiliza de forno de micro-ondas, de telefonia celular e, conforme o professor P1 nos aponta, "o cotidiano deles é usar radiação de micro-ondas, né usar celular" porém os conteúdos que sustentam o funcionamento de tais dispositivos, quando tratados, são apenas com aspecto superficial. No modelo tradicional de ensino, fica complexo ao professor abordar tais conceitos pelas diversas contingências do espaço disponível para o ensino de FMC no ensino médio.

Entretanto a proposta construtivista de Papert (2008) pode representar, nesse caso, uma luz, no aspecto de que o construcionismo não só se situa como uma proposta metodológica mais efetiva de ensino como permite a utilização de novas tecnologias para a informação e a comunicação. Tal metodologia posiciona o aprendiz não apenas puramente como operador, mas utilizando tais tecnologias de forma que esse usuário conjectura em sua mente, desenvolvendo, ou melhor, construindo o conhecimento, de modo a não apenas ser treinado pelo equipamento, mas aprender a aprender (PAPERT, 2008).

O primeiro questionamento, feito aos alunos, tratava de investigar quais eram as suas percepções sobre uma tempestade solar. Os alunos foram instigados a refletir sobre tal assunto após a leitura de uma notícia de um evento que produziu grande destruição, depois de uma tempestade solar ter atingido o planeta Terra. Com essa motivação, tiveram de responder sobre como uma tempestade solar, vinda, portanto, de fora do planeta Terra, poderia produzir malefícios à sociedade.

Entre as respostas, destacamos a seguinte, do aluno A2: "a tempestade solar emite partículas radioativas essa radiação poderia afetar os satélites e comprometer os meios de comunicação poderiam afetar também o campo magnético da terra podendo trazer futuros problemas climáticos". O mesmo aluno, quando questionado sobre a possibilidade de observar essas partículas advindas do espaço, apontou que "não podemos observá-las pois não são visíveis ao olho humano devido ao seu tamanho e estrutura".

A falta de compreensão de aspectos da FMC pode conduzir os alunos ao julgamento incorreto, dada a sua falta de conhecimento nesses aspectos. Assim, ainda nas respostas iniciais dos alunos podemos observar descrições como a do aluno A16: "Porque estão sendo liberadas por uma fonte radioativa que nos 
prejudica. Por que as partículas também são radioativas e quando elas atingem grande quantidade podemos ter problemas à saúde, tanto na estrutura"; outro aluno A15: "como são partículas são de Alta Energia acredito que com a junção delas aumenta ainda mais a energia, portanto quando ela se encontra com a Alta Energia que aqui na terra causa essa tamanha destruição".

O aluno A7 aponta que "as partículas danificam ou destrói todos os aparelhos elétricos em seu caminho como a sobrecarga de energia levando a grandes catástrofes a lugares dependentes do funcionamento de aparelhos elétricos como a regulagem de usinas nucleares". Todas as respostas iniciais denotaram uma visão ingênua da existência das partículas de altas-energias. Contudo, considerando a necessidade de uma alfabetização científica, conforme Praia, Gil-Pérez e Vilches (2007), "Existe um amplo consenso acerca da necessidade de uma alfabetização científica que permita preparar as cidadãs e os cidadãos para a tomada de decisões".

Desse modo, o experimento, proposto neste estudo, permitiu que os professores pudessem aproximar o conteúdo tratado da realidade dos alunos, pois, conforme a resposta do aluno $\mathrm{A} 13$, quando questionado sobre $\mathrm{O}$ conhecimento prévio da existência das partículas fundamentais presentes no experimento: "sim, antes tinha apenas o conceito teórico, com o experimento fui capaz de visualizar na prática". A atividade experimental, portanto, possibilitou trazer a existência das partículas de altas energias para a realidade do alunado. Conforme a resposta do aluno A4, "Na câmara de nuvens foi observado partículas, que normalmente permanecem "invisíveis" aos nossos olhos. Entre as partículas, há traços com três diferenças onde uma apresentava traço fino, outro grosso e por último ondulado". Outro aluno, A22, aponta que "vimos partículas alfa e elétrons, elas possuem cargas diferentes, e por isso tomam direções diferentes".

O aluno A6 indica que "o conhecimento sobre as partículas é sim existente, porém a sua origem e função não eram imaginadas [...], após o experimento, a compreensão foi ampliada e foi deixando, de maneira clara, a importância das partículas em nossas vidas". A câmara de nuvens é um dispositivo de deteç̧ão de partículas carregadas, pois apenas partículas carregadas eletricamente serão capazes de produzir a ionização necessária para formar as gotículas esperadas para percebermos a passagem de uma partícula (LAGANÁ, 2011).

O marcante nas respostas dos alunos é perceber a compreensão de que existe um fenômeno ocorrendo na câmara e que este fenômeno também ocorre na sala de aula, porém o efeito não se revela por conta da ausência de um meio que permita a observação. Nossa intervenção permitiu então que esses alunos tivessem mudança em seu modo de perceber o mundo a partir da utilização de um recurso didático que contempla as novas tecnologias da informação e comunicação.

\section{COMO VEJO O MUNDO}

Nessa categoria pretendemos abordar como os alunos e os professores percebem o mundo que os rodeia. O aluno A27 nos reporta que "a percepção humana é limitada a certo tamanho", enquanto o aluno A3, para a mesma questão, revela, anteriormente ao experimento, que "As partículas têm formatos variados e são coloridas" e o mesmo aluno aponta sobre a ação dessas partículas 
no ambiente que "as partículas alteram o meio ambiente, pois são quentes, $e$ quando entram em contato com a matéria vão acabar queimando e danificando elas".

Podemos identificar nessas respostas novamente uma percepção muito superficial dos fenômenos decorrentes da interação de partículas com a matéria. Contudo, após a realização do experimento, a entrevistado professor P1 relatou, sobre a participação dos alunos na atividade, que "eles ficaram muito empolgados e ficaram curiosos sobre o que são neutrinos, de onde vêm e pude trabalhar com maior profundidade o conteúdo do que em anos anteriores".

Isso nos revelou que ocorreu aproximação entre os alunos e o conteúdo. Corroborando nossa conclusão, temos a resposta do aluno A20: "atividades como essa melhora o nosso entendimento com a física". Alguns alunos apontaram a necessidade de utilizar um dispositivo para permitir a visualização das partículas, conforme a fala de A6: "Não conseguimos observar essas partículas a olho nu, precisamos de um aparelho especializado conseguirmos vê-las", de modo a compreender essa percepção da necessidade de instrumentos para revelar o comportamento da natureza.

Além dessas falas, ainda somos apoiados pela percepção de A23: "o tempo nublado foi algo que dificultou na observação, pois a água absorve as partículas". Notamos que o aluno foi capaz de relacionar os eventos ocorridos na câmara de nuvens com os eventos que ocorrem em uma nuvem, assim, por extensão, o aluno alegou que, se na câmara havia interação entre as partículas advindas do espaço e a nuvem de vapor supersaturado de álcool, deveria na nuvem de vapor de água ocorrer o mesmo fenômeno.

Verificamos que interação realizada se mostrou conveniente quando se pôde, segundo os professores, apresentar fatos da natureza da ciência (PRAIA, GILPÉREZ, VILCHES, 2007), no que tange à necessidade de se construir aparatos para estudar determinados fenômenos de modo que o paradigma vigente é o fio condutor para a produção do experimento. Conforme Kuhn (2011, p.72), "os paradigmas orientam as pesquisas, seja modelando-as diretamente, seja através de regras abstratas". Assim, vemos as possibilidades emergentes de uma ação experimental como a desenvolvida.

Conforme discutimos nestas seções de análise, evidenciamos que a intervenção utilizando o laboratório de acesso remoto, para observar radiação cósmica, teve alguma influência sobre o modo como esses alunos passaram a perceber a disciplina de física e a maneira como veem o mundo que os rodeia.

\section{A REALIDADE DAS TECNOLOGIAS EM SALA DE AULA}

A sociedade atual está permeada de tecnologias de informação. Estas são ainda tecnologias com funcionamento desconhecido à maioria de seus usuários. $\mathrm{A}$ realidade da sala de aula, conforme verificamos em questionamento aos alunos e conforme pesquisa realizada pelo Comitê Gestor da Internet no Brasil, os jovens em idade escolar estão conectados a estruturas de rede e se utilizam de dispositivos móveis, o que lhes permite manter a conexão com a rede de computadores, mesmo quando em trânsito entre lugares distantes. 
Segundo a antecipação de Mcluhan (1964), estaríamos hoje realmente em uma aldeia global. Contudo ainda carecemos utilizar essas ferramentas de rede para melhoria da vida de todos. Segundo dados do Comitê Gestor da Internet no Brasil em seu relatório de 2015 , temos que $87 \%$ dos alunos brasileiros utilizam-se de celular (smartphone) como principal ferramenta de conexão à internet (D'AVO, 2015, p. 439).

Porém o potencial de utilização de tais tecnologias de informação para o ensino, especificadamente para o ensino de FMC, ainda é subutilizado pois os alunos desta geração, bem como os docentes, em sua maioria ainda encaram as tecnologias de informação como algo desconhecido (LÉVY, 1999).

Quanto aos conceitos físicos, estudados neste trabalho, encontramos, com as falas dos alunos, uma dependência do uso da técnica. E essa abordagem se sustenta nas definições de Lévy (1999) pois esse autor aponta que a sociedade é condicionada pela técnica e, quanto mais distante a compreensão da técnica, mais condicionada a sociedade estará aos limites e possibilidades dessa técnica.

Podemos observar a fala do aluno A7 que descreve: "Para enxergarmos estas partículas precisaríamos de equipamentos apropriados", ou na fala de A15 a qual mostra a necessidade de "A invenção de um super-microscópio específico para elementos pequenos". Além dessas, temos a fala do aluno A3: "O que devemos fazer é investimentos na área da física, química e informática, pois até hoje não conseguimos pensar em uma maneira eficaz de enxergar essas partículas, então o desenvolvimento de novas tecnologias é o ideal". O que fica explícito nessas falas é a compreensão, por parte dos alunos, da necessidade de uma técnica ou ferramenta para a evidenciação do fenômeno.

Isso representa a compreensão de que as técnicas providas pela cultura permitirão o desenvolvimento da percepção de novos fenômenos, antes até desconhecidos, o que pode realimentar o sistema de melhoria da técnica, influenciando novamente os contornos da sociedade (LÉVY, 1999).

Outro ponto de vista, na percepção dos alunos, emerge na fala de A27 o qual nos revela: "Para enxergá-las seria necessário uma quantidade imensa de partículas num mesmo espaço com explosões solares.". Assim, além da carência de um dispositivo tecnológico que permita a observação do fenômeno, ainda há uma concentração limite, abaixo da qual não perceberíamos o fato, de modo que a técnica novamente presente é o ponto de ligação da observação com a realidade.

Uma vez que os alunos buscam construir uma explicação aos questionamentos impostos e conduzidos ao ciclo descrição-execução-reflexãodepuração-descrição, é possível que as ações construcionistas de ensino permitam favorecer a compreensão dos conceitos subjacentes estudados, melhorando o letramento tecnológico dos envolvidos. Pois, conforme Valente (1998) nos aponta, no início acreditava-se que os computadores poderiam ensinar os humanos, dada a crença na tecnologia informática. Contudo hoje sabemos que os computadores nos ajudam no aprendizado, pois temos de ensiná-los a resolver nossos problemas.

\section{CONCLUSÃO}

O ensino de FMC carece de novas metodologias e novos recursos didáticos, com vistas a permitir a expansão de seu ensino para etapas escolares como o 
ensino médio. Segundo Lino (2013, p.77.), entre os motivos para se ensinar FMC no ensino médio, destaca-se o "subsídio à compreensão e crítica das questões atuais que envolvem ciência, tecnologia sociedade e ambiente". Conforme descrevemos, as pesquisas com vistas na construção de recursos para experimentos relacionados à $\mathrm{FMC}$ têm-se desenvolvido na educação, contudo a sua efetiva inserção na escola esbarra em problemas como a falta de preparação dos professores, a dificuldade de espaços físicos e laboratórios nas escolas, a falta de recursos para aquisição dos equipamentos, os quais, em muitos casos, não são encontrados com muita facilidade em todas as cidades brasileiras.

Dessa forma, refletir em novos formatos de estratégias educacionais é relevante para sanar tais dificuldades. Como apontamos, um laboratório que pode estar alocado em uma universidade e que pode ser utilizado remotamente por escolas em âmbito mundial representa uma nova possibilidade para contornar alguns dos problemas supracitados.

Contudo um laboratório sem a devida orientação metodológica não trará garantia de resultados favoráveis ao aprendizado. Dessa forma, além de o equipamento estar disponível aos professores e alunos, faz-se necessário fornecer adequada formação continuada aos docentes, para que estes estejam devidamente preparados para promover o ensino adequado.

Conforme as análises nos revelaram, a intervenção experimental, conciliada com a proposta educacional construcionista, produziu efeitos positivos na aprendizagem dos conteúdos trabalhados, posicionando o laboratório de acesso remoto como um elemento facilitador para o ensino de física de partículas para o ensino médio. Tal conclusão se sustenta nos relatos dos alunos após a realização da atividade experimental, bem como na fala dos professores indicando uma aproximação dos alunos com a disciplina. Dessa forma, destacamos que esta pesquisa forneceu, para o ensino de física moderna e contemporânea, a possibilidade de realizarmos atividades experimentais sem a necessidade de um laboratório local, permitindo o estudo de um conceito tão importante para a compreensão da natureza, que são os raios cósmicos, e favorecendo a experimentação em um conteúdo muitas vezes abordado de forma teórica e sem o devido aprofundamento necessário à sua compreensão. Além dessa contribuição, verificamos avanços no aspecto da compreensão por parte dos estudantes de fenômenos antes desconhecidos, e o conhecimento se limitava apenas a uma realidade teorizada anteriormente, aproximando, assim, a teoria da realidade desses aprendizes. 


\title{
Conceptions about the inclusion of a remote access laboratory with a contemporary physics experiment
}

\begin{abstract}
Modern and contemporary physics constitute a highly developed scientific field, being the theoretical basis for the operation of numerous devices, thus producing a wide range of applications used in everyday life in today's society. There are several problems associated with the inclusion of these subjects in secondary education, among which one can mention the costs of implanting laboratories with experiments in modern physics topics for all public schools. Besides these costs, there is also a need for teacher preparation, for the application of a methodological strategy that allows the discussion of such topics with the students, guaranteeing the learning. For this research the objective of investigating the pedagogical potential of a remote access laboratory for the teaching of modern and contemporary physics (FMC) in high school. And, in order to achieve the above general objective, we have as specific objectives of our work to identify, through the FMC teaching activities, the influence of the use of a remote access laboratory in the development of the experimental activity with third year students of secondary education with the physical curricular component; Analyze the use of experimental activities as a methodological strategy to provide benefits for learning FMC concepts. A remote access laboratory was developed and the experiment used in this investigation was a cloud chamber. The sequence of teaching used guaranteed actions outlined by the description-execution-reflection-debugging cycle, proposed by the constructionist theory, by Valente and Papert. During the actions were conducted interviews with the teachers and questionnaires were applied to the participating students. The transcribed responses were analyzed according to the technique of discursive textual analysis, such answers allowed to verify the potentialities of use of the remote access laboratory as a facilitator of the inclusion of FMC topics in high school.
\end{abstract}

KEYWORDS: Constructionism. Remote access. Modern physics. High school. 


\section{REFERÊNCIAS}

BRASIL. Ministério da Educação. Secretaria de Educação Básica. PCN+ - Ensino Médio: Orientações Educacionais Complementares aos Parâmetros Curriculares Nacionais - FíSICA. Brasília: MEC/SEB, 2002, 40 p.

BROCKINGTON, G. e PIETROCOLA, M. O Ensino de Física Moderna necessita ser real?.In: XVI SNEF - Simpósio Nacional de Ensino de Física, 2005, Rio de Janeiro. Atas do XVI SNEF.

D'AVO, C. (Brasil). Comitê Gestor da Internet no Brasil (Ed.). TIC EDUCAÇÃO 2015: Pesquisa sobre o uso das tic nas escolas brasileiras. São Paulo: Cetic, 2016. $490 \mathrm{p}$.

HALLIDAY, D.; RESNICK, R. e WALKER J. Fundamentos de física volume 4: óptica e física moderna. 10 ed. Rio de Janeiro: LTC, 2016.

HOFSTEIN, A.; NAAMAN, R. M. The laboratory in science education: the state of the art. Chem. Educ. Res. Pract., Londres, v. 8, p. 105-107, 2007.

KUHN, T. S. A Estrutura das Revoluções Científicas. 10 ed. Ed. Perspectiva. São Paulo. 2011. 260p

LAGANÁ, C. Estudo de raios cósmicos utilizando uma câmara de nuvens de baixo custo.Revista Brasileira de Ensino de Física, v. 33, n. 3, 3302 (2011)

LAKATOS, E. M.; MARCONI, M. D. A. Técnicas de pesquisa: planejamento e execução de pesquisas, amostragens e técnicas de pesquisas, elaboração, análise e interpretação de dados. 3ạ ed. São Paulo: Atlas, 1996.

LEAL, S. C.; FERNANDES, H.; LEAL, J. P. Plataforma e-lab potencia o ensino / aprendizagem das ciências no ensino básico e secundário. Noesis Online.p. 1-14. Disponível em <http://www.academia.edu/1875260/Plataforma_elab_potencia_o_ensino_aprendizagem_das_ciencias_no_ensino_basico_e_secun dario>Acessado em 25 de outubro de 2012.

LÉVY, P. Cibercultura. Tradução de Carlos Irineu da Costa. 1ạ ed. São Paulo: Ed. 34, 1999, 264 p.

LINO, A, SILVA, J. R. N. da, ARENGHI,L. E. B.. Porque inserir física moderna e acadêmicos. Revista Brasileira de Ensino de Ciências e Tecnologias, vol6, núm. 1, jan-abr. 2013 
MA, J.; NICKERSON, J. V.; Hands-On, Simulated, and Remote Laboratories: A Comparative Literature Review. ACM Computing Surveys, vol. 38, n3, art.7, Nova York. Set. De 2006.

MALTEMPI, M.V. Construção de Páginas Web: Depuração e Especificação de um Ambiente de Aprendizagem. 2000. 186 p. Tese - Faculdade de Engenharia Elétrica e de Computação da Universidade Estadual de Campinas. Campinas. 2000.

MCLUHAN, H. M. Understanding Media: the Extensions of Man. New York: McGraw-Hill, 1964

MORAES, Roque. Uma tempestade de luz: a compreensão possibilitada pela análise textual discursiva. Ciênc. educ. (Bauru), Bauru, v. 9, n. 2, p. 191-211, 2003

MOREIRA, M. A. Física de Partículas: Uma Abordagem Conceitual e Epistemológica. São Paulo: Edusp, 2012. 143 p.

OGIBOSKI, L. Laboratório Remoto Baseado em Software Livre para Realização de Experimentos Didáticos. 2007. 93 p. Dissertação - Escola Politécnica da Universidade de São Paulo. São Paulo. 2007.

OSTERMANN, F.; MOREIRA, M. A. Física contemporánea en La escuela secundaria: uma experiencia en el aula involucrando formación de profesores. Enseñanza de las ciencias, Barcelona: v.18, n.3, p.391-404, 2000.

PAPERT, S. A Máquina das Crianças: repensando a escola na era da informática. ed. rev. Porto Alegre: Artmed, 2008, 224 p.

PIETROCOLA, M. Modern Physics In Brazilian Secondary Schools. In: International Conference on Physics Education, 2005, Nova Delhi: ICPE, 2005

PRAIA, J., GIL-PÉREZ, D., Vilches, A. O Papel da Natureza da Ciência na Educação Para a Cidadania. Ciência \& Educação, v. 13, n. 2, p. 141-156, 2007

ROBERTS, R. Using Different Types of Practical Within a Problem-Solving Model of Science. Scho. Scien. Rev., 85 (312), p. 113-119, Herts. Mar. de 2004.

STAKE, R. E. Pesquisa Qualitativa: estudando como as coisas funcionam; trad.: Karla Reis. Porto Alegre: Penso, 2011263 p. 
TERRAZZAN, E. A. A inserção da física moderna e contemporânea no ensino de física na escola de 2으. grau. Caderno Catarinense de Ensino de Física, Florianópolis, v. 9, n. 3, p. 209-214, dez. 1992.

TAYLOR, B. Designed for teaching, Education+Training, v. 8, n.7 p.316-317, 1966

VALENTE, J. A.; Mudanças na sociedade, mudanças na educação: 0 fazer e o compreender In: VALENTE, J. A. (org.) O computador na Sociedade do Conhecimento. Campinas: UNICAMP, 1999. p. 29-37. Cap.2.

VALENTE, J.A. \& CANHETTE, C.C. LEGO-Logo: explorando o conceito de design. In: VALENTE, J.A. (org.) Computadores e conhecimento: repensando a educação. Campinas, Gráfica da UNICAMP. 1993. p.64-75.

ZABALA, A. A Prática Educativa: como ensinar. trad. Ernani F. da F. R. Porto Alegre: Artmed, 1998, $224 \mathrm{p}$.

Recebido: 2017-03-02

Aprovado: 2018-01-31

DOI: $10.3895 /$ rbect.v11n1.5623

Como citar: LUCIANO, A.; FUSINATO, P. A. Concepções acerca da inclusão de um laboratório de acesso remoto com experimentos de física contemporânea. Revista Brasileira de Ensino de Ciência e Tecnologia, v. 11, n. 1, 2018. Disponível em: <https://periodicos.utfpr.edu.br/rbect/article/view/5623>. Acesso em: xxx. Correspondência: Arquimedes Luciano - arquimedes.luciano@hotmail.com Direito autoral: Este artigo está licenciado sob os termos da Licença Creative Commons-Atribuição 4.0 Internacional. 